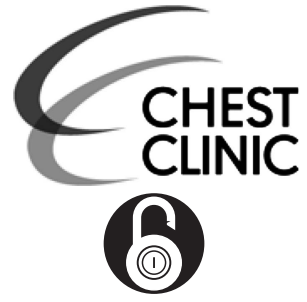

\section{OPEN ACCESS}

${ }^{1}$ Department of Occupational and Environmental Medicine, Imperial College (NHLI) and Royal Brompton Hospital, London, UK

${ }^{2}$ Health Management Limited, London, UK

${ }^{3}$ Department of Respiratory Medicine, Northwick Park Hospital, London, UK

${ }^{4}$ Centre for Workplace Health, Northern General Hospital, Brearley Outpatient, Herries Road, Sheffield, UK

\section{Correspondence to} Dr Paul Cullinan, Department of Occupational and Environmental Medicine, Imperial College (NHLI) and Royal Brompton Hospital, 1 b Manresa Road, London SW3 6LR, UK; p.cullinan@imperial.ac.uk

Received 4 June 2014 Revised 24 June 2014 Accepted 25 June 2014 Published Online First

8 July 2014
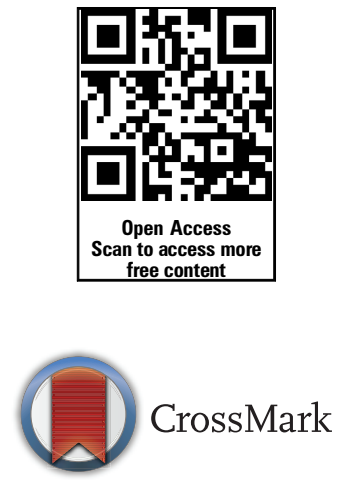

To cite: Cullinan $P$, D'Souza E, Tennant R, et al. Thorax 2014;69. 1059-1060.

\title{
Lesson of the month: extrinsic allergic (bronchiolo) alveolitis and metal working fluids
}

\author{
Paul Cullinan, ${ }^{1}$ Eva D'Souza, ${ }^{2}$ Rachel Tennant, ${ }^{3}$ Chris Barber ${ }^{4}$
}

\section{INTRODUCTION}

One of us was asked to consider a diagnosis of occupational asthma for a man who had worked for 20 years as a metal turner in a large, modern factory producing specialised machine parts. $\mathrm{He}$ described a 2 year history of severe breathlessness that improved when he was not at work. His spirometry was restrictive with a $\mathrm{FEV}_{1}$ of $1.35 \mathrm{~L}(40 \%$ predicted) and FVC of $1.8 \mathrm{~L}$ (45\% predicted), a ratio of $75 \%$. Other lung function measurements indicated gas trapping; his TLC was $5.01 \mathrm{~L}(79 \%$ predicted) and RV/TLC $170 \%$ predicted. A high resolution CT scan of his lungs revealed a widespread 'mosaic' pattern of attenuation indicative of small airflow obstruction. We made a diagnosis of occupational extrinsic allergic bronchioloalveolitis and recommended that he change his work. After 12 months working elsewhere in the same company, away from the machine shop, his dyspnoea was greatly improved but had not disappeared; his FVC had increased to $2.41 \mathrm{~L}$, his $\mathrm{FEV}_{1}$ to $1.45 \mathrm{~L}$ and his TLC to $5.36 \mathrm{~L}$.

Four months later we were referred a man who was also a metal turner in the same factory. For 2 years he had been a patient in a specialist interstitial lung disease clinic with a diagnosis of chronic hypersensitivity pneumonitis. A marked lymphocytosis in his bronchoalveolar lavage suggested ongoing exposure to an external cause. The nature of this had not been established although the positive findings of an autoimmune screen had led to conjecture of an 'autoimmune' aetiology, and of a high level of serum-specific IgG antibodies to Aspergillus species, that exposure to 'mould at home or work' might be relevant; an occupational history noted only that he worked for a machine parts manufacturer. While continuing to work he had been treated with pulsed methylprednisolone, cyclophosphamide, prednisolone, mycophenolate and $\mathrm{N}$-acetyl cysteine with little evidence of success. His referral was occasioned by a (new) physician noting that his symptoms improved when he was not at work. On being informed that his illness was in all probability caused by his occupation, he chose not to return to work. Six months later, without any specific treatment, his lung function measurements had started to improve.

Following the first diagnosis, discussion with the factory's occupational health service led to a systematic survey of 250 employees who worked in the same area. Through this we established that another metal turner was a patient at a third hospital with a diagnosis of hypersensitivity pneumonitis made 2 years previously; to his bemusement, since he had never kept them, a probable attribution to 'birds' had been made. He had been treated, intermittently, with high doses of prednisolone with no evidence of lasting benefit. The survey of other employees and subsequent specialist investigation established a further two cases of occupational bronchioloalveolitis with probable onset in 2010-2011.

\section{DISCUSSION}

These five men had a diagnosis and an occupation in common; all were metal machinists in a single factory, a job that entails exposure to mists of metal working fluids (MWFs). Inhalation of MWF is well recognised as a cause of extrinsic allergic bronchioloalveolitis (in this context a more accurate term than hypersensitivity pneumonitis), ${ }^{12}$ but it appears, from this experience, that the association is not widely appreciated by respiratory physicians.

Machining or 'turning' metal parts on a lathe is a skilled occupation used in the manufacture of a very wide variety of components; this is often done using cutting tools controlled by a computer and metalworking machinists in the UK and elsewhere may describe themselves as "computer numerical control' operators. Other terms include computer numerical control grinder, turner, tool setter, cutter and machinist. Metal shaping and grinding commonly involves the use of MWF (in the UK also known as 'coolant', 'cutting fluid' or 'suds') to lubricate the process, to control its temperature and to carry away the waste metal ('swarf'). The machines are generally enclosed and may be exhaust-ventilated to reduce-but rarely eliminate - the escape of MWF mist into the atmosphere. MWF is collected and recirculated, often with several machines sharing a common 'sump' or reservoir. Systems of MWF management are required to replenish and maintain its effectiveness and to monitor levels of microbial contamination. In the factory above, new lathes had been installed in 2010 ; in contrast with those they replaced, the new machines were capable of being operated continuously for $24 \mathrm{~h}$ and used a far higher volume of MWF. These changes probably led to far higher concentrations of MWF mist in the air of the shop floor.

Most modern MWFs are complex emulsions of water and a mineral, synthetic or semisynthetic oil; they also contain a wide range of chemical additives designed to enhance their performance and limit microbial growth. Allergic respiratory conditions due to water-containing MWFs date back to the late 1980s, with challenge studies confirming cases 
of occupational asthma caused by chemicals such as ethanolamine and pine oil deodorants. ${ }^{2}$ More recently, a number of large outbreaks of respiratory disease have been reported in US and European MWF-exposed workers, with cases of extrinsic allergic (bronchiolo)alveolitis (EAA), occupational asthma, bronchitis and humidifier fever. ${ }^{2}$ Although difficult to prove, the aetiology of the outbreaks is thought to be due to poor control of MWF mists, linked with microbial contamination occurring during their recirculation and prolonged use. Evidence to support this comes from the unpredictable nature of the outbreaks and the demonstration of $\operatorname{IgG}$ antibodies to a range of bacteria, fungi and environmental mycobacteria in the serum of exposed workers (with and without disease). ${ }^{3}$

A high index of suspicion is required in EAA due to MWF exposure as the symptoms are often non-specific and may be progressive, rather than clearly work-related. In some cases the presenting symptoms have been predominantly constitutional, with general malaise and unexplained weight loss. Long delays in reaching the correct diagnosis are not uncommon because symptoms are often attributed to asthma, COPD or to recurrent chest infections; or, as here, the diagnosis has been otherwise explained. A HRCT with inspiratory and expiratory views in a period when the patient is symptomatic is probably the most useful diagnostic tool. This may show typical features of bronchioloalveolitis, with one or more of ground glass opacities, small centrilobular nodules and lobular areas of gas trapping ${ }^{4}$ although this last finding is not specific. In other cases however, the HRCT may appear normal (particularly during periods of relatively low exposure), or show a pattern of disease more suggestive of nonspecific or usual interstitial pneumonitis. As with any other cause of EAA, early recognition and the prevention of further exposures offer the best outcome; as with all occupational diseases, every effort should be made to maintain employment and relocate affected workers to a safe, non-exposed work role.

An additional consideration is that the patient who has EAA from MWF may have a number (sometimes several hundred) of colleagues with similar exposures. ${ }^{3}$ The diagnosis of a single case should prompt the workplace to review their risk assessment and exposure controls, and to survey the remaining workforce to identify other affected workers. Investigating large outbreaks is logistically challenging, and where possible should involve a multidisciplinary team including occupational lung disease specialists, occupational health providers and occupational hygienists. ${ }^{5}$ In the outbreak above, careful scrutiny of all exposed employees indicated that the problem was confined to a small area of the shop floor; following extensive remedial works to control MWF mists there have been no further cases.

Over the last decade, MWF exposure has become the most commonly reported cause of occupational EAA in the UK, responsible for approximately half of all cases. We recommend that all patients with suspected EAA (and other patterns of interstitial lung disease) are routinely asked about MWF exposures, and that all potential cases are discussed as soon as possible with an occupational lung disease centre.

Correction notice This article has been corrected since it was Published Online First. The author Chris Barber's affiliation has been amended.

Contributors $\mathrm{PC}$ and RT identified the cases and wrote the manuscript with the assistance of $E D$ and $C B$.

\section{Competing interests None.}

Provenance and peer review Not commissioned; internally peer reviewed.

Open Access This is an Open Access article distributed in accordance with the Creative Commons Attribution Non Commercial (CC BY-NC 4.0) license, which permits others to distribute, remix, adapt, build upon this work non-commercially, and license their derivative works on different terms, provided the original work is properly cited and the use is non-commercial. See: http://creativecommons.org/ licenses/by-nc/4.0/

\section{REFERENCES}

1 Rosenman KD. Asthma, hypersensitivity pneumonitis and other respiratory diseases caused by metalworking fluids. Curr Opin Allergy Clin Immunol 2009;9:97-102.

2 Burton CM, Crook B, Scaife H, et al. Systematic review of respiratory outbreaks associated with exposure to water-based metalworking fluids. Ann Occup Hyg 2012;56:374-88.

3 Barber $\mathrm{CM}$, Burton $\mathrm{CM}$, Robinson $\mathrm{E}$, et al. Hypersensitivity pneumonitis due to metalworking fluid exposures. Chest 2013;143:1189.

4 Gaeta M, Minutoli F, Girbino G, et al. Expiratory CT scan in patients with normal inspiratory CT scan: a finding of obliterative bronchiolitis and other causes of bronchiolar obstruction. Multidiscip Respir Med 20013:8:1-86.

5 Robertson W, Robertson AS, Burge CB, et al. Clinical investigation of an outbreak of alveolitis and asthma in a car engine manufacturing plant. Thorax 2007;62:981-90. 